\title{
Rare metastases of differentiated thyroid carcinoma: pictorial review
}

\author{
Hong-Jun Song ${ }^{1}$, Yan-Li Xue ${ }^{1,2}$, Yan-Hong X ${ }^{1,2}$, Zhong-Ling Qiu ${ }^{1}$ \\ and Quan-Yong Luo ${ }^{1}$
}

\author{
${ }^{1}$ Department of Nuclear Medicine, Shanghai Sixth People's Hospital, Shanghai Jiao Tong University, 600 Yishan Road, Shanghai \\ 200233, China \\ ${ }^{2}$ Postgraduate Department, Soochow University, 1 Shizi Road, Suzhou 215006, China \\ (Correspondence should be addressed to Q-Y Luo; Email: Iqyn@sh163.net)
}

\begin{abstract}
Differentiated thyroid cancer (DTC) is usually indolent with good prognosis and long-term survival. However, DTC distant metastasis is often a grave event and accounts for most of its diseasespecific mortality. The major sites of distant metastases are the lung and bone. Metastases to the brain, breast, liver, kidney, muscle, and skin are rare or relatively rare. Nevertheless, recognizing rare metastases from DTC has a significant impact on the clinical decision making and prognosis of patients. ${ }^{131} \mathrm{I}$ single photon emission computed tomography/computed tomography $\left({ }^{131} \mathrm{I}\right.$-SPECT/CT) can provide both metabolic and anatomic information about a lesion; therefore, it can better localize and define the ${ }^{131}$ I-WBS findings in DTC patients. In this pictorial review, the imaging features of a range of rare metastases from DTC are demonstrated, with a particular emphasis on the ${ }^{131}$ I-SPECT/CT diagnostic aspect.
\end{abstract}

Endocrine-Related Cancer (2011) 18 R165-R174

\section{Introduction}

Papillary and follicular carcinomas of the thyroid gland often referred to together as differentiated thyroid cancer (DTC), are characterized by a slowly progressive course, and a 10-year survival rate as high as $80-95 \%$ (Schlumberger 1998). It usually remains localized to the thyroid gland. Distant metastases are seen in a minority of patients and the reported rates of occurrence range from 4 to $15 \%$ (Hoie et al. 1988, Casara et al. 1993, Shaha et al. 1997, Clark et al. 2005, Aggarwal et al. 2007). The most common site of distant metastases is the lung, followed by the bone (Mazzaferri \& Massoll 2002). Other distant metastases are rare or relatively rare and involve the brain, breast, liver, kidney, muscle, and skin. The presence of distant metastases is the most significant poor prognostic factor for survival, with only $50 \%$ metastatic patients surviving after 10 years (Elisei et al. 2010). Among the factors responsible for distant metastases and increased mortality in patients with DTC are age over 45 years and the involvement of multiple organs, both are independently associated with cancer mortality (Ruegemer et al. 1988). The common distant metastasis sites (lung and bone) from DTC usually draw significant concern and are well known to us. However, rare metastases, due to their extremely low incidence, are usually not taken into account or are ignored in the clinical setting. Nevertheless, recognizing the patterns of rare metastases from DTC has a significant impact on the clinical decision making and prognosis of patients.

Because of its high sensitivity and specificity, posttherapeutic ${ }^{131} \mathrm{I}$-WBS and ${ }^{131} \mathrm{I}$ single photon emission computed tomography/computed tomography $\left({ }^{131} \mathrm{I}-\right.$ SPECT/CT) currently remain indispensable for the management of patients with DTC. ${ }^{131} \mathrm{I}$-SPECT/CT is of incremental value over ${ }^{131} \mathrm{I}$-WBS at increasing diagnostic accuracy, reducing pitfalls, and modifying therapeutic strategies (Spanu et al. 2009). Owing to the use of ${ }^{131} \mathrm{I}$-SPECT/CT imaging fusion techniques, rare metastasis in DTC is increasingly becoming an incidental finding (Chen et al. 2008, Qiu et al. 2011). This pictorial review highlights the diagnostic aspects of ${ }^{131}$ I-SPECT/CT for the localization and definition of rare metastases in DTC patients.

\section{Brain metastasis}

Brain metastases are extremely rare, reportedly occurring in roughly $0.15-1.3 \%$ of thyroid carcinomas 

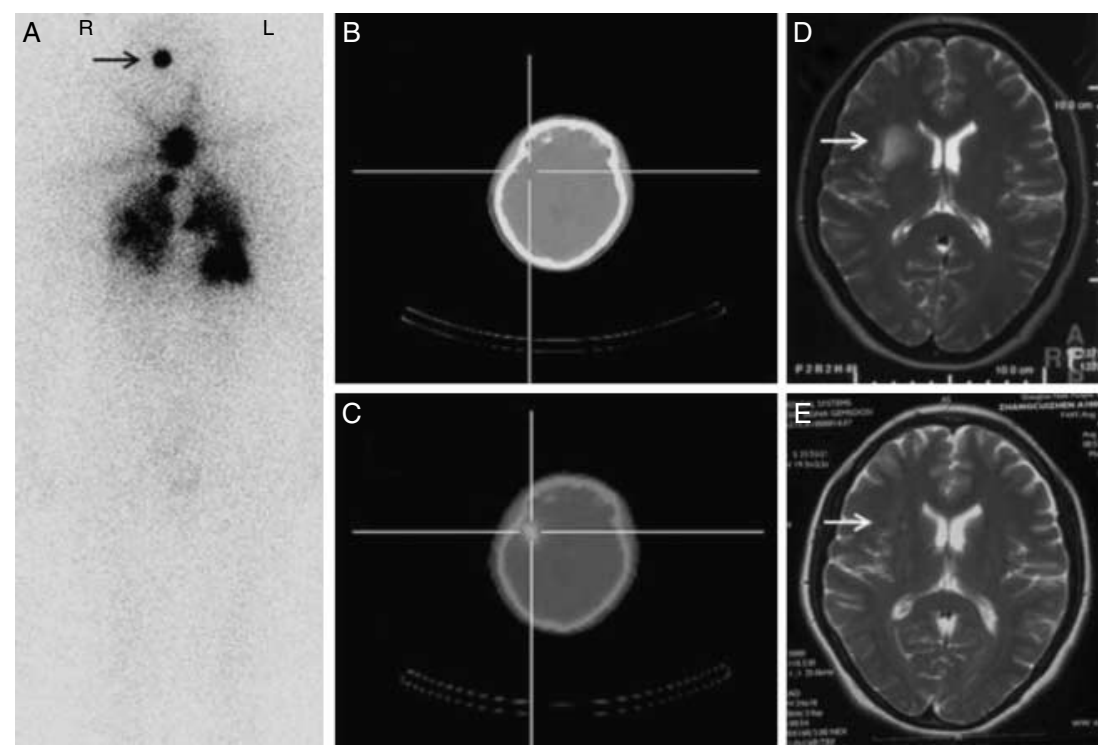

Figure $1{ }^{131} \mathrm{I}$-WBS, ${ }^{131} \mathrm{I}$-SPECT/CT, and magnetic resonance imaging (MRI) from a patient with brain metastases of papillary thyroid microcarcinoma. She was treated with $3.7 \mathrm{GBq}$ of ${ }^{131} \mathrm{I}$ for ablation of the post-surgical thyroid remnant and treatment of the lung metastases. Post-therapy ${ }^{131} \mathrm{I}$-WBS revealed a single cephalic uptake $(A)$ of ${ }^{131} \mathrm{I}$ in addition to the cervical and pulmonary uptake. ${ }^{131}$ I-SPET/CT fusion images showed cephalic foci located in the right side of the cerebrum (B and C). Further examination with MRI revealed a solitary metastatic lesion in the area of the right internal capsule of the cerebrum, with marked peritumoral edema extending from the tumor margin (D). MRI scan images obtained 3 months after the radiosurgery showed that the peritumoral edema had nearly disappeared along with almost complete response of the lesion (E). Reproduced, with permission, from Xu et al. (2011a).

(Parker et al. 1986). However, in all rare metastases, the brain was the most frequent locus of secondary metastasis from DTC in a study of a large cohort of patients (Dinneen et al. 1995). Dinneen et al. (1995)

noted that $\sim 18 \%$ of patients with distant metastases from PTC developed brain metastases during their disease course. It occurs more frequently in the cerebral hemispheres (Fig. 1); other sites for

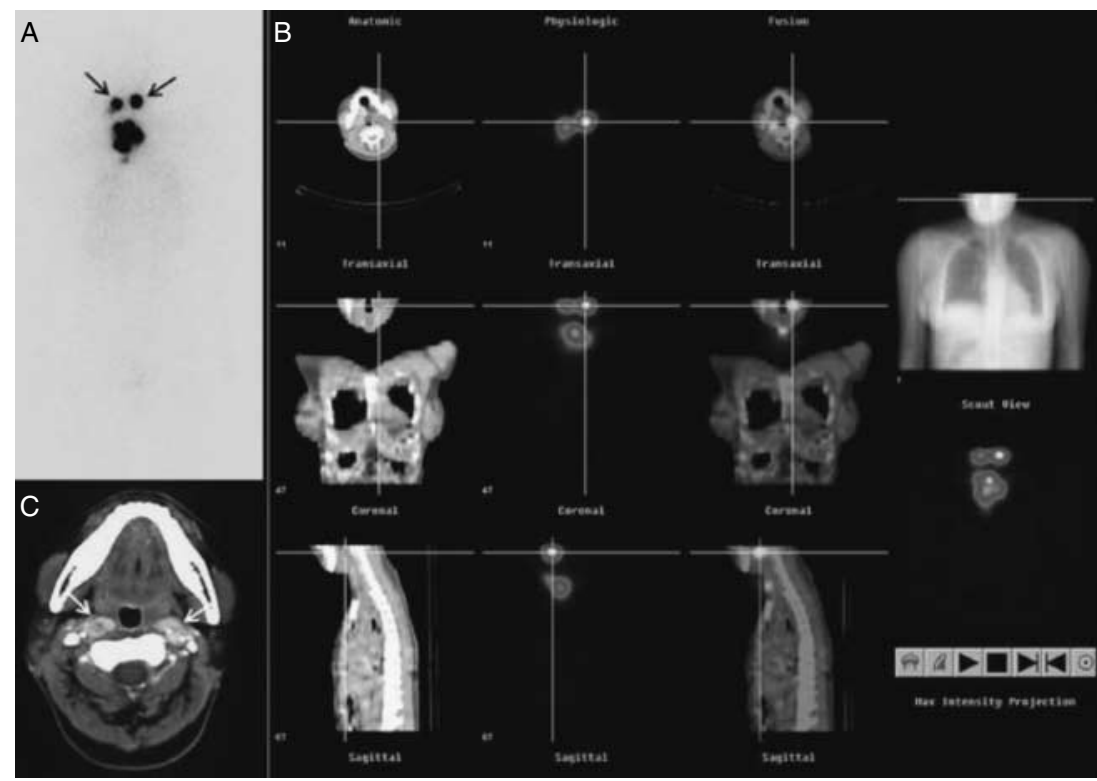

Figure 2 A 26-year-old female with papillary thyroid cancer after thyroidectomy was treated with 3.7 GBq of ${ }^{131}$ I for ablation of the post-surgical thyroid remnant. ${ }^{131} \mathrm{I}$-WBS and ${ }^{131} \mathrm{I}$-SPECT/CT were performed after ${ }^{131} \mathrm{I}$ therapy. Anterior ${ }^{131} \mathrm{I}$-WBS imaging detected two abnormal ${ }^{131} \mathrm{I}$ uptake foci in the pharyngeal region (A, black arrows). ${ }^{131} \mathrm{I}$-SPECT/CT provided metabolic and anatomic information that the two foci of ${ }^{131}$ I uptake were localized in the left and right parapharyngeal spaces (B). High-resolution contrast-enhanced CT scans indicated left and right parapharyngeal masses (C, white arrows). Reproduced, with permission, from Qiu et al. (2011). 

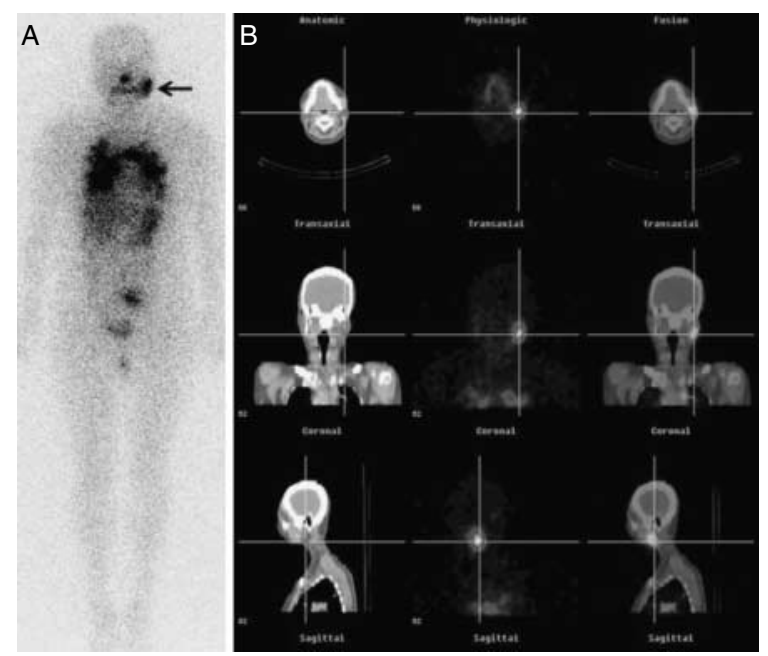

Figure 3 A 55-year-old woman who had a 4-year history of follicular thyroid cancer received ${ }^{131} \mathrm{I}$ therapy for the treatment of lung metastases. Post-therapeutic ${ }^{131}$ I-WBS incidentally detected abnormal foci of ${ }^{131}$ I uptake in the left facial region (A, black arrow). ${ }^{131}$ I-SPECT/CT localized the lesion of ${ }^{131}$ I uptake in the left parotid gland, which was suspected of being metastasis because of the asymmetric ${ }^{131}$ I uptake in the bilateral parotids (B). Surgical pathology confirmed the diagnosis of the left parotid metastasis.

intracranial metastases are the cerebellum (PazaitouPanayiotou et al. 2005, Al-Dhahri et al. 2009) and pituitary (Chrisoulidou et al. 2004, Yilmazlar et al. 2004). Brain metastases are usually asymptomatic, and only a few have suggestive symptoms, including headache, visual disturbances, or ocular motor weakness. There is a general consensus in the literature that brain metastasis is associated with poor prognosis with a tendency for recurrence (Al-Dhahri et al. 2009).

\section{Parapharyngeal metastasis}

Parapharyngeal metastasis from DTC is quite rare, accounting for only $0.5 \%$ of all head and neck tumors (Pang et al. 2002). Totally, two relatively large numbers of DTC cases with parapharyngeal metastases have been described, suggesting that the incidence rate of parapharyngeal metastasis is extremely low (Desuter et al. 2004). Parapharyngeal mass is often nonspecific or asymptomatic when the tumor does not exceed $3.0 \mathrm{~cm}$ in size (Tomoda et al. 2005). Frequently, patients complain of a mass in the neck or oropharynx that causes dysphagia. Most parapharyngeal metastases are unilateral, whereas some rare cases are bilateral (Fig. 2). Integrated ${ }^{131} \mathrm{I}$-SPECT/CT is a useful tool for the screening of parapharyngeal metastasis in patients with DTC, especially earlier parapharyngeal metastasis (Qiu et al. 2011). Parapharyngeal metastasis should be included in the differential diagnosis of parapharyngeal masses.

\section{Parotid metastasis}

Involvement of the parotid gland from DTC is extremely rare and is mostly detected at autopsy (Alzaraa et al. 2008). In an analysis of 108 cases, three cases of a metastatic thyroid cancer metastasizing to the parotid were reported, with secondary metastases to the salivary glands (Seifert et al. 1986). Typically, it is an incidental finding in the clinical setting (Fig. 3).

\section{Breast metastasis}

Metastasis to the breast from DTC is extremely rare. To date, only 11 cases have been described in the
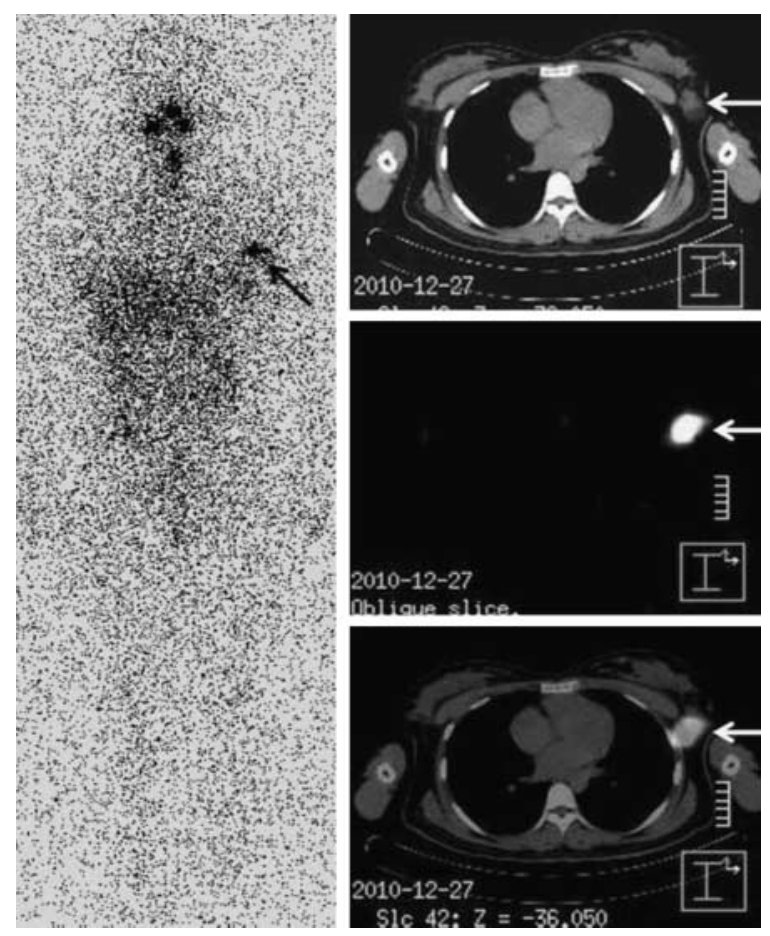

Figure 4 A 28-year-old woman with papillary thyroid cancer was treated with ${ }^{131}$ I for ablation of a post-surgical thyroid remnant. An unexpected focus of abnormal ${ }^{131} I$ uptake in the superficial left chest wall was observed on the post-ablation ${ }^{131}$ I-WBS ( $A$, shown by arrow), and it was difficult to decide whether it was a real lesion or a site of ${ }^{131}$ I contamination on the skin based on the planar images alone. Therefore, ${ }^{131}$ I-SPECT/CT was performed to accurately localize the foci of ${ }^{131}$ I uptake. The images clearly showed that the abnormal ${ }^{131}$ I uptake in the left chest wall was located in the left vice-mammary gland $(B, C$, and D). Finally, ultrasound-guided fine needle aspiration (FNA) demonstrated that the lesion was metastasis from papillary thyroid cancer. 

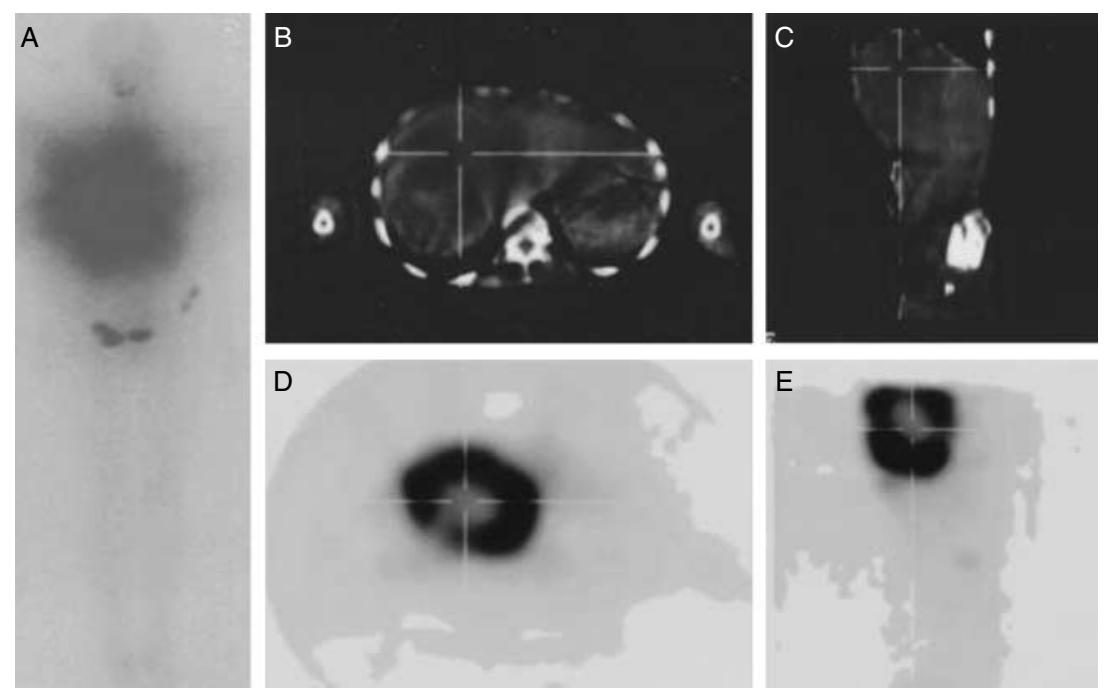

Figure $5^{131}$ I-WBS and ${ }^{131}$ I-SPECT/CT fusion images from a patient who received a thyroidectomy for follicular thyroid cancer. After 25 years, she was treated with $7.4 \mathrm{GBq}$ of ${ }^{131} \mathrm{I}$ for bone metastases in the pelvis. Post-therapeutic ${ }^{131} \mathrm{I}$-WBS demonstrated a star, irregular, and intense radioactivity signature in the right upper part of the abdomen in addition to the pelvic uptake. (A). To accurately locate the ${ }^{131}$ I uptake lesion, ${ }^{131} \mathrm{I}-\mathrm{SPECT} / \mathrm{CT}$ was performed and the ${ }^{131} \mathrm{I}$ uptake was localized in a large liver mass (B, C, D, and E). Fine needle aspiration confirmed the diagnosis of liver metastasis from follicular thyroid cancer.

literature (Chisholm et al. 1980, Tan et al. 1991, Cristallini et al. 1994, Loureiro et al. 1997, Fiche et al. 1998, Al-Abed et al. 2008, Angeles-Angeles et al. 2009). All of the patients were female, with four papillary and three follicular types in the primary tumor. Vice-mammary gland metastasis from DTC is even rare (Fig. 4) and has not been reported to date. Breast metastasis usually occurs in the setting of disseminating metastases. However, Loureiro et al. (1997) reported a unique case of a follicular variant of papillary thyroid carcinoma, with three cutaneous and one breast metastases in the absence of other sites of dissemination. It seems that metastatic disease to the breast tends to be superficial and usually located at the upper outer quadrant. Metastases to the breast are associated with poor prognosis.

\section{Liver metastasis}

Liver metastasis from DTC is a rare event, with a reported frequency of $0.5 \%$ (Salvatori et al. 2004). Only ten cases have been documented in the literature; three were males and seven were females, with an average age of about 63 years (range from 32 to 85 years). Histologically, the primary tumor was identified as papillary in four patients, follicular in five patients, and Hurthle cell thyroid cancer in one patient. Liver masses can be detected by various imaging modalities, such as ultrasonography and CT, and are usually ${ }^{131} \mathrm{I}$ negative. ${ }^{131}$ I-positive metastases are extremely rare (Fig. 5). DTC liver metastasis has a poor prognosis. Surgical resection of liver lesions has been reported to offer the best chance for prolonged survival (Niederle et al. 1986).
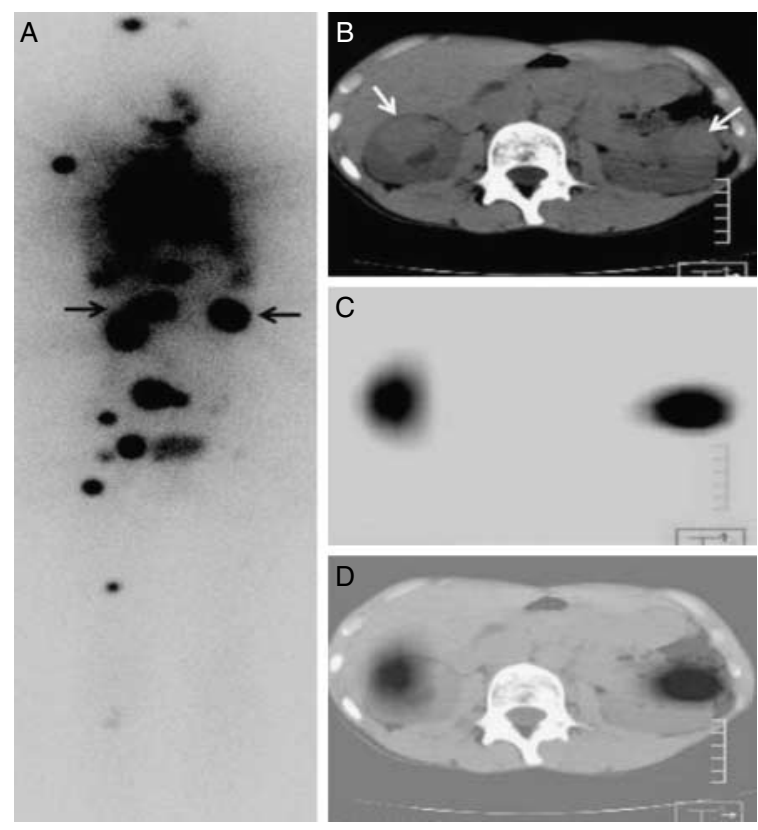

Figure 6 A 19-year-old patient who had a 8-year history of papillary thyroid cancer developed systemic multiple metastases. Post-therapeutic ${ }^{131} \mathrm{I}$-WBS showed strong focal tracer uptake in the regions of the head, lung, abdomen, and limbs $(A)$. The ${ }^{131}$ I uptake in the abdominal region (A, shown by arrows) drew our attention. Subsequent ${ }^{131}$ I-SPECT/CT of the abdomen revealed two separate lesions that were localized in the bilateral renal masses (B-D). 

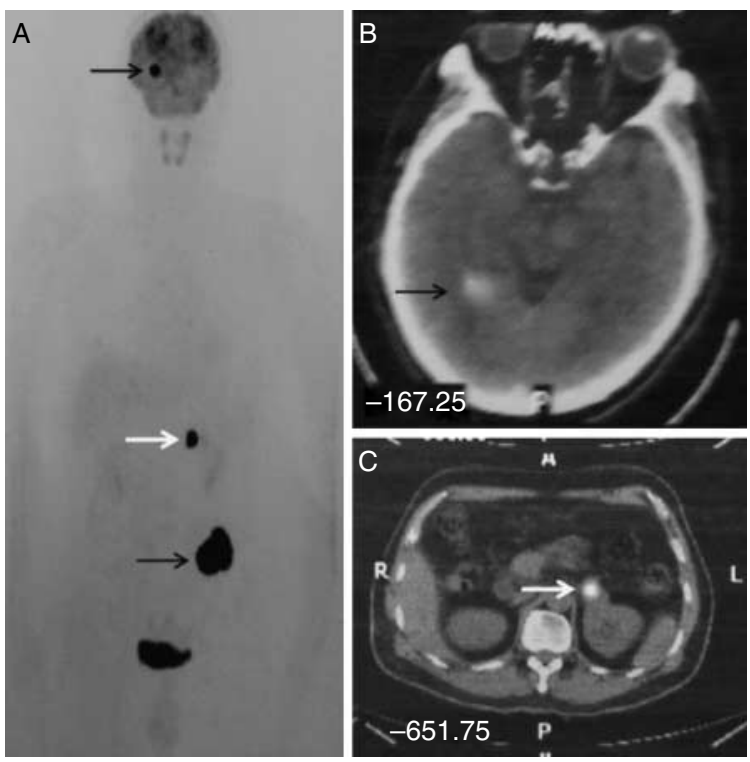

Figure 7 A patient was given ${ }^{131}$ I treatment after total thyroidectomy. No abnormal ${ }^{131}$ I uptake was found in the posttherapeutic ${ }^{131}$ I-WBS; however, the serum thyroglobulin (Tg) was $2569 \mathrm{ng} / \mathrm{ml}$. ${ }^{18} \mathrm{~F}$-fluorodeoxyglucose positron emission tomography/computed tomography ( $\left.{ }^{18} \mathrm{FDG}-\mathrm{PET} / \mathrm{CT}\right)$ was performed to search for potential metastatic lesions (A). Three ${ }^{18} \mathrm{FDG}$-positive lesions were found in the right cerebrum (B), left adrenal gland (C), and iliac bone. Negative ${ }^{131}$ I-WBS but elevated Tg levels in DTC patients is indicative of metastatic disease. ${ }^{18} \mathrm{FDG}-\mathrm{PET} / \mathrm{CT}$ can localize the source of $\mathrm{Tg}$ production and identify the metastases by their enhanced glucose metabolism. Reproduced, with permission, from Xu et al. (2011a).
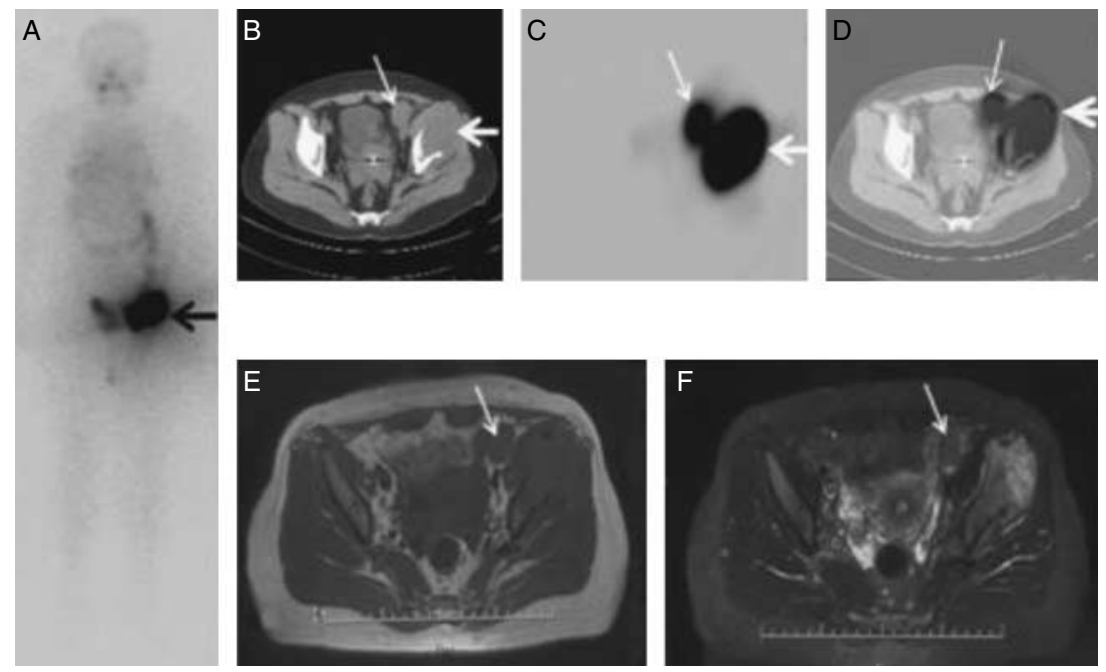

Figure 8 A 42-year-old woman was treated with ${ }^{131}$ I for ilium metastasis from papillary thyroid cancer. Post-therapeutic ${ }^{131}$ I-WBS showed intense ${ }^{131} \mathrm{I}$ uptake in the left pelvis (A, black arrow). ${ }^{131} \mathrm{I}-\mathrm{SPECT} / \mathrm{CT}$ fusion scans were performed to localize and identify the pelvic lesion. What surprised us was that the pelvis ${ }^{131}$ I uptake was not only a pelvic ${ }^{131}$ I uptake lesion in the left ilium (B, C, D, thick white arrow) but also a separate solid mass in the pelvic cavity (B, C, D, thin white arrow). MRI of the pelvis found that the mass in the pelvic cavity was most likely an ovarian lesion (E, F, thin white arrow). Finally, the mass was histologically confirmed to be an ovarian metastasis from papillary thyroid cancer. Reproduced, with permission, from Xu et al. (2011b). 


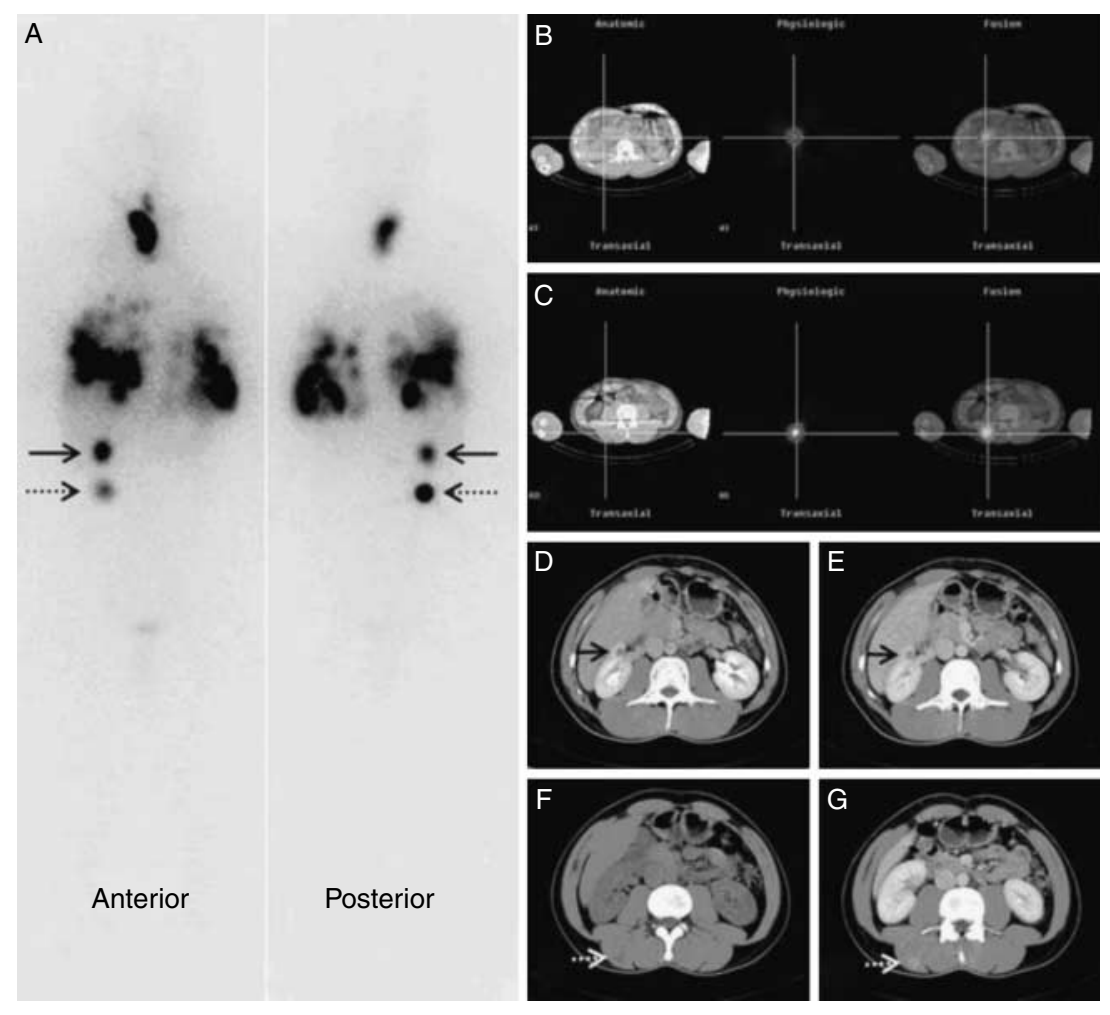

Figure 9 A 29-year-old patient presenting with locoregional lymph nodes and pulmonary metastases from papillary thyroid cancer was treated with ${ }^{131} \mathrm{I}$. The post-therapeutic ${ }^{131} \mathrm{I}$-WBS revealed two abdominal foci of ${ }^{131} \mathrm{I}$ uptake (A, solid line arrows and dashed line arrows) in addition to the cervical and pulmonary uptake. The ${ }^{131}$ I-SPECT/CT fusion images identified abdominal foci located in the area of the right kidney (B) and lower back muscle (C). High-resolution CT further confirmed a solitary lesion on the upper pole of the right kidney (D, E, solid line arrow) and a solitary lesion in the right erector spinae ( $F, G$, dashed line arrow). Reproduced, with permission, from Luo et al. (2008).

been reported by Orsolon et al. (1996). Although adrenal and renal metastases are closely related in terms of anatomy, concomitant adrenal and renal metastases from DTC are exceptional, as only two cases have been reported in the literature (Kumar et al. 2005, Malhotra et al. 2010). ${ }^{131}$ I-avid adrenal metastasis is very rare. Koutkia \& Safer (2001) described the first case of a solitary, functioning adrenal metastasis secondary to papillary thyroid carcinoma, and it was found by ${ }^{131} \mathrm{I}-\mathrm{WBS}$. The majority of adrenal metastases are detected by other medical imaging modalities (Fig. 7).

\section{Ovarian metastasis}

The rarity of ovarian metastasis from DTC is supported by a review of the literature, where only three cases have been reported (Young et al. 1994, Logani et al. 2001, Brogioni et al. 2007). It seems that ovarian metastasis tends to occur unilaterally rather than bilaterally (Fig. 8). Bilateral ovarian metastasis from papillary thyroid cancer has been reported by Brogioni et al. (2007). Ovarian metastasis from DTC tends to occur many years after the primary tumor is discovered. Because of the long intervals, when there is a woman who presents with a cystic ovarian mass, the differential diagnoses to consider should include ovarian metastasis from DTC. Therefore, the patient history should be thoroughly investigated for evidence of a prior neoplasm in the thyroid gland.

\section{Muscle metastasis}

Although more than $40 \%$ of the total human weight comprises skeletal muscle, hematogenous metastasis to skeletal muscle is extremely rare. A hypothesis is that skeletal muscle is a hostile environment for the retention and proliferation of cancer cells, including muscle motion, unadapted muscle $\mathrm{pH}$, and the muscle's ability to remove tumor-produced lactic acid (Seely 1980). A retrospective review of the literature revealed only ten reports of DTC muscle metastases. It seems that DTC is prone to metastasizing to the erector spinae, as three of the ten cases were erector spinae metastases (Luo et al. 2008, Qiu \& Luo 2009). Muscle metastases are generally associated with other distant 

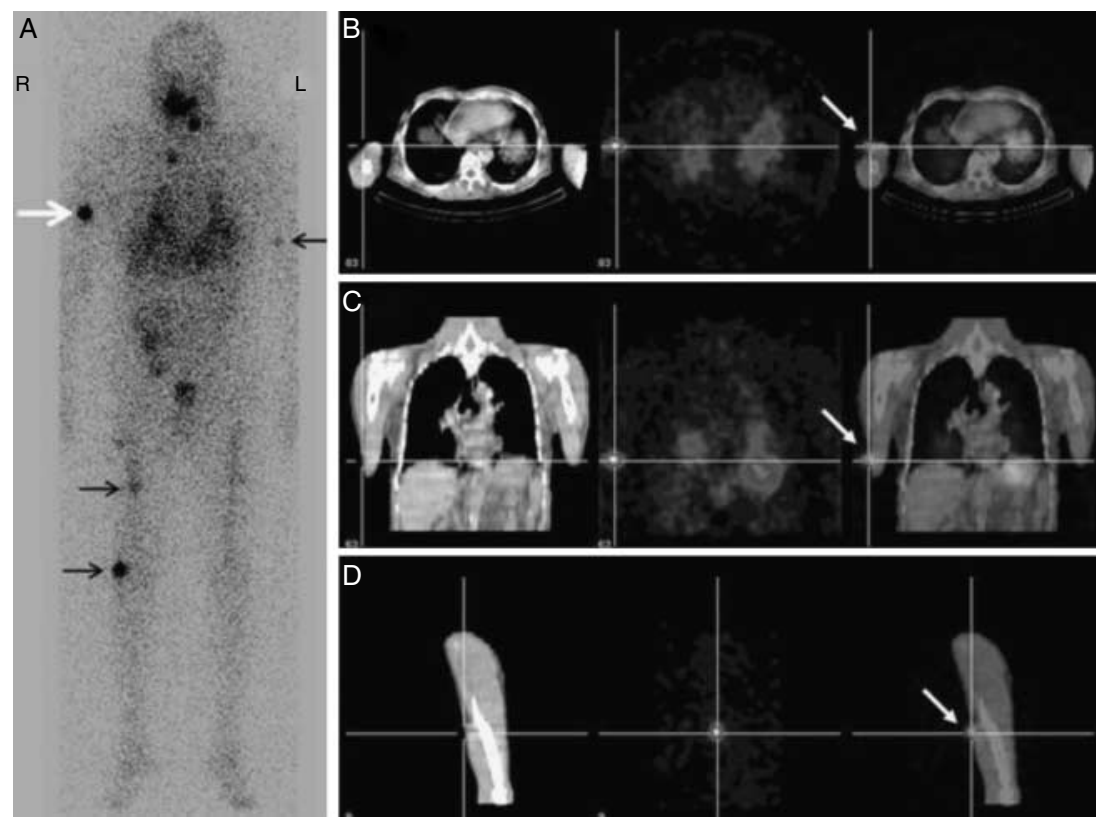

Figure $10{ }^{131}$ I-WBS and ${ }^{131}$ I-SPECT/CT fusion images of multiple subdermal metastases from papillary thyroid cancer. The posttherapeutic ${ }^{131}$ I-WBS showed several rounded foci of ${ }^{131}$ I uptake in the upper and lower limbs, which were thought to be skin contamination by ${ }^{131} \mathrm{I}$ (A). However, subsequent ${ }^{131} \mathrm{I}$-SPECT/CT revealed lesions that were localized in the subdermal region (B, C, and D); these were found to correlate with the subdermal nodules. Finally, the subdermal nodules were histologically confirmed to be skin metastases from papillary thyroid cancer by FNA. Reproduced, with permission, from Luo et al. (2008).

metastases (Fig. 9). An elderly hyperthyroid patient presented with single metastasis in the right arm bicep without any other metastasis (Pucci et al. 2006). Most skeletal muscle metastases are neither painful nor palpable; therefore, muscle metastases tend to be an incidental finding in the clinical setting.

\section{Skin metastasis}

DTC skin metastasis typically presents as slowly growing erythematous or nodules, usually on the scalp, face, or neck. The scalp is the most common site, being involved in approximately two-thirds of cases (Dahl et al. 1997). This may relate to local vascular factors essential for the highly complex nature of metastasis (Avram et al. 2004). Cutaneous metastases in the genital area are less common. Shon et al. (2010) reported the first case of ulcerated skin nodules in the scrotum from Hurthle cell carcinoma of the thyroid. Limb skin metastasis is rare (Fig. 10). Skin lesions may be solitary or multiple and are almost always asymptomatic. Ulceration is uncommon. Varma et al. (2007) reported three clinically interesting cases of papillary cancer presenting with skin ulceration. Although the presence of cutaneous metastases in patients with thyroid cancer portends a poor prognosis, understanding the clinical manifestation determines the overall management of the patients.

\section{Summary and conclusion}

In conclusion, DTC, which ordinarily behaves in an indolent manner, can have unusual metastatic presentations and patterns. ${ }^{131} \mathrm{I}$-WBS and ${ }^{131} \mathrm{I}$-SPECT/CT play an important role in the management of patients with DTC. With the popularity of ${ }^{131}$ I treatment and the emergence of ${ }^{131} \mathrm{I}$-SPECT/CT fusion imaging techniques, rare metastases in DTC may not be as rare as we once thought and may be increasingly common. Increasing importance should be given to rare metastases in DTC patients. This review highlights the need for an awareness of the possibility of unique metastatic deposits of DTC at unexpected sites. Care should be taken to determine whether ${ }^{131}$ I uptake found at an unexpected site is DTC metastasis or false-positive uptake.

\section{Declaration of interest}

The authors declare that there is no conflict of interest that could be perceived as prejudicing the impartiality of the review reported.

\section{Funding}

This research did not receive any specific grant from any funding agency in the public, commercial or not-for-profit sector. 


\section{References}

Aggarwal V, Bhargav PR, Mishra A \& Agarwal G 2007 Clinico-pathological characteristics and long-term outcome in patients with distant metastases from differentiated thyroid carcinoma. World Journal of Surgery 31 246-247. (doi:10.1007/s00268-006-0546-y)

Al-Abed Y, Gray E, Wolfe K, Watters GW \& Philpott JM 2008 Metastatic hurthle cell carcinoma of the thyroid presenting as a breast lump: a case report. International Seminars in Surgical Oncology 5 14. (doi:10.1186/14777800-5-14)

Al-Dhahri SF, Al-Amro AS, Al-Shakwer W \& Terkawi AS 2009 Cerebellar mass as a primary presentation of papillary thyroid carcinoma: case report and literature review. Head \& Neck Oncology 1 23. (doi:10.1186/17583284-1-23)

Alzaraa A, Stone J, Williams G, Ahmed I \& Quraishi M 2008 Direct spread of thyroid follicular carcinoma to the parotid gland and the internal jugular vein: a case report. Journal of Medical Case Reports 2 297. (doi:10.1186/ 1752-1947-2-297)

Angeles-Angeles A, Chable-Montero F, Martinez-Benitez B \& Albores-Saavedra J 2009 Unusual metastases of papillary thyroid carcinoma: report of 2 cases. Annals of Diagnostic Pathology 13 189-196. (doi:10.1016/ j.anndiagpath.2008.02.010)

Avram AM, Gielczyk R, Su L, Vine AK \& Sisson JC 2004 Choroidal and skin metastases from papillary thyroid cancer: case and a review of the literature. Journal of Clinical Endocrinology and Metabolism 89 5303-5307. (doi:10.1210/jc.2004-0757)

Brogioni S, Viacava P, Tomisti L, Martino E \& Macchia E 2007 A special case of bilateral ovarian metastases in a woman with papillary carcinoma of the thyroid. Experimental and Clinical Endocrinology \& Diabetes 115 397-400. (doi:10.1055/s-2007-973853)

Brucker-Davis F, Reynolds JC, Skarulis MC, Fraker DL, Alexander HR, Weintraub BD \& Robbins J 1996 Falsepositive iodine-131 whole-body scans due to cholecystitis and sebaceous cyst. Journal of Nuclear Medicine 37 1690-1693.

Casara D, Rubello D, Saladini G, Masarotto G, Favero A, Girelli ME \& Busnardo B 1993 Different features of pulmonary metastases in differentiated thyroid cancer: natural history and multivariate statistical analysis of prognostic variables. Journal of Nuclear Medicine $\mathbf{3 4}$ 1626-1631.

Chen L, Luo Q, Shen Y, Yu Y, Yuan Z, Lu H \& Zhu R 2008 Incremental value of ${ }^{131} \mathrm{I}$-SPECT/CT in the management of patients with differentiated thyroid carcinoma. Journal of Nuclear Medicine 49 1952-1957. (doi:10. 2967/jnumed.108.052399)

Chisholm RC, Chung EB, Tuckson W, Khan T \& White JE 1980 Follicular carcinoma of the thyroid with metastasis to the breast. Journal of the National Medical Association 72 1101-1104.
Chrisoulidou A, Pazaitou-Panayiotou K, Flaris N, Drimonitis A, Giavroglou I, Glinikopoulou E \& Vainas I 2004 Pituitary metastases of follicular carcinoma. Hormone Research 61 190-192. (doi:10.1159/ 000076387)

Clark JR, Lai P, Hall F, Borglund A, Eski S \& Freeman JL 2005 Variable predicting distant metastases in thyroid cancer. Laryngoscope 115 661-667. (doi:10.1097/01.mlg. 0000161337.46892.e0)

Cristallini EG, Ascani S, Nati S, Liberati F \& Farabi R 1994 Breast metastasis of thyroid follicular carcinoma. Acta Oncologica 33 71-73. (doi:10.3109/ 02841869409098381)

Dahl PR, Brodland DG, Goellner JR \& Hay ID 1997 Thyroid carcinoma metastatic to the skin: a cutaneous manifestation of a widely disseminated malignancy. Journal of the American Academy of Dermatology 36 531-537. (doi:10.1016/S0190-9622(97)70239-1)

Desuter G, Lonneux M, Plouin-Gaudon I, Jamar F, Coche E, Weynand B, Rahier J, Grégoire V, Andry G \& Hamoir M 2004 Parapharyngeal metastases from thyroid cancer. European Journal of Surgical Oncology 30 80-84. (doi:10.1016/j.ejso.2003.10.004)

Dinneen SF, Valimaki MJ, Bergstralh EJ, Goellner JR, Gorman CA \& Hay ID 1995 Distant metastases in papillary thyroid carcinoma: 100 cases observed at one institution during 5 decades. Journal of Clinical Endocrinology and Metabolism 80 2041-2045. (doi:10.1210/jc.80.7.2041)

Elisei R, Molinaro E, Agate L, Bottici V, Masserini L, Ceccarelli C, Lippi F, Grasso L, Basolo F, Bevilacqua G et al. 2010 Are the clinical and pathological features of differentiated thyroid carcinoma really changed over the last 35 years? Study on 4187 patients from a single Italian institution to answer this question Journal of Clinical Endocrinology and Metabolism 95 1516-1527. (doi:10. 1210/jc.2009-1536)

Fiche M, Cassagnau E, Aillet G, Bailly J, Chupin M, Classe JM \& Bodic MF 1998 Breast metastasis from a "tall cell variant" of papillary thyroid carcinoma. Annales de Pathologie 18 130-132.

Graham LD \& Roe SM 1995 Metastatic papillary thyroid carcinoma presenting as a primary renal neoplasm. American Surgeon 61 732-734.

Hoie J, Stenwig AE, Kullmann G \& Lindegaard M 1988 Distant metastases in papillary thyroid cancer. A review of 91 patients. Cancer 61 1-6. (doi:10.1002/10970142(19880101)61:1<1::AID-CNCR2820610102>3.0. $\mathrm{CO} ; 2-\mathrm{R})$

Koutkia P \& Safer JD 2001 Adrenal metastasis secondary to papillary thyroid carcinoma. Thyroid 11 1077-1079. (doi:10.1089/105072501753271798)

Kumar A, Nadig M, Patra V, Srivastava DN, Verma K \& Bal CS 2005 Adrenal and renal metastases from follicular thyroid cancer. British Journal of Radiology $\mathbf{7 8}$ 1038-1041. (doi:10.1259/bjr/24024066) 
Langsteger W, Koltringer P, Meister E \& Eber O 1993 False positive scans in papillary thyroid carcinoma. Journal of Nuclear Medicine 342280.

Liou MJ, Lin JD, Chung MH, Liau CT \& Hsueh C 2005 Renal metastasis from papillary thyroid microcarcinoma. Acta Oto-Laryngologica 125 438-442. (doi:10.1080/ 00016480410022822)

Logani S, Baloch ZW \& Snyder PJ 2001 Cystic ovarian metastasis from papillary thyroid carcinoma: a case report. Thyroid 11 1073-1075. (doi:10.1089/ 105072501753271789)

Loureiro MM, Leite VH, Boavida JM, Raposo JF, Henriques MM, Limbert ES \& Sobrinho LG 1997 An unusual case of papillary carcinoma of the thyroid with cutaneous and breast metastases only. European Journal of Endocrinology 137 267-269. (doi:10.1530/eje.0.1370267)

Luo Q, Luo QY, Sheng SW, Chen LB, Yu YL, Lu HK \& Zhu RS 2008 Localization of concomitant metastases to kidney and erector spinae from papillary thyroid carcinoma using (131)I-SPECT and CT. Thyroid $\mathbf{1 8}$ 663-664. (doi:10.1089/thy.2007.0326)

Malhotra G, Upadhye TS, Sridhar E, Asopa RV, Garde PS, Gawde S \& Rangarajan V 2010 Unusual case of adrenal and renal metastases from papillary carcinoma of thyroid. Clinical Nuclear Medicine 35 731-736. (doi:10.1097/ RLU.0b013e3181ea342b)

Mazzaferri EL \& Massoll N 2002 Management of papillary and follicular (differentiated) thyroid cancer: new paradigms using recombinant human thyrotropin. EndocrineRelated Cancer 9 227-247. (doi:10.1677/erc.0.0090227)

McDougall IR 1995 Whole-body scintigraphy with radioiodine-131. A comprehensive list of false-positives with some examples. Clinical Nuclear Medicine 20 869-875. (doi:10.1097/00003072-199510000-00002)

Niederle B, Roka R, Schemper M, Fritsch A, Weissel M \& Ramach W 1986 Surgical treatment of distant metastases in differentiated thyroid cancer: indications and results. Surgery 100 1088-1096.

Orsolon P, Bagni B, Geatti O \& Guerra UP 1996 An unusual adrenal metastasis secondary to Hurthle cell carcinoma of the thyroid. Clinical Nuclear Medicine 21 312-315. (doi:10.1097/00003072-199604000-00011)

Pang KP, Goh CH \& Tan HM 2002 Parapharyngeal space tumours: an 18 year review. Journal of Laryngology and Otology 116 170-175. (doi:10.1258/ 0022215021910447)

Parker LN, Wu SY, Kim DD, Kollin J \& Prasasvinichai S 1986 Recurrence of papillary thyroid carcinoma presenting as a focal neurologic deficit. Archives of Internal Medicine 146 1985-1987. (doi:10.1001/ archinte.146.10.1985)

Pazaitou-Panayiotou K, Kaprara A, Chrisoulidou A, Boudina M, Georgiou E, Patakiouta F, Drimonitis A \& Vainas I 2005 Cerebellar metastasis as first metastasis from papillary thyroid carcinoma. Endocrine Journal $\mathbf{5 2}$ 653-657. (doi:10.1507/endocrj.52.653)
Pucci A, Suppo M, Lucchesi G, Celeste A, Viberti L, Pellerito R \& Papotti M 2006 Papillary thyroid carcinoma presenting as a solitary soft tissue arm metastasis in an elderly hyperthyroid patient. Case report and review of the literature. Virchows Archiv: an International Journal of Pathology 448 857-861. (doi:10.1007/s00428006-0187-4)

Qiu ZL \& Luo QY 2009 Erector spinae metastases from differentiated thyroid cancer identified by I-131 SPECT/CT. Clinical Nuclear Medicine 34 137-140. (doi:10.1097/RLU.0b013e31819675b6)

Qiu ZL, Xu YH, Song HJ \& Luo QY 2011 Localization and identification of parapharyngeal metastases from differentiated thyroid carcinoma by ${ }^{131}$ I-SPECT/CT. Head \& Neck 33 171-177. (doi:10.1002/hed.21416)

Ruegemer JJ, Hay ID, Bergstralh EJ, Ryan JJ, Offord KP \& Gorman CA 1988 Distant metastases in differentiated thyroid carcinoma: a multivariate analysis of prognostic variables. Journal of Clinical Endocrinology and Metabolism 67 501-508. (doi:10.1210/jcem-67-3-501)

Ruggiero FP, Frauenhoffer EE \& Stack BC Jr 2005 Papillary thyroid cancer with an initial presentation of abdominal and flank pain. American Journal of Otolaryngology 26 142-145. (doi:10.1016/j.amjoto. 2004.08.008)

Salvatori M, Perotti G, Rufini V, Maussier ML, Summaria V, Fadda G \& Troncone L 2004 Solitary liver metastasis from Hürthle cell thyroid cancer: a case report and review of the literature. Journal of Endocrinological Investigation 27 52-56.

Schlumberger MJ 1998 Papillary and follicular thyroid carcinoma. New England Journal of Medicine 338 297-306. (doi:10.1056/NEJM199801293380506)

Seely S 1980 Possible reasons for high resistance of muscle to cancer. Medical Hypotheses 6 133-137. (doi:10.1016/ 0306-9877(80)90079-1)

Seifert G, Hennings K \& Caselitz J 1986 Metastatic tumours to the parotid and submandibular glands - analysis and differential diagnosis of 108 cases. Pathology, Research and Practice 181 684-692.

Shaha AR, Shah JP \& Loree TR 1997 Differentiated thyroid cancer presenting initially with distant metastasis. American Journal of Surgery 174 474-476. (doi:10.1016/ S0002-9610(97)00158-X)

Shon W, Ferguson SB \& Comfere NI 2010 Metastatic Hürthle cell carcinoma of the thyroid presenting as ulcerated scrotum nodules. American Journal of Dermatopathology 32 392-394. (doi:10.1097/DAD. 0b013e3181c1acaf)

Spanu A, Solinas ME, Chessa F, Sanna D, Nuvoli S \& Madeddu G $2009{ }^{131}$ I-SPECT/CT in the follow-up of differentiated thyroid carcinoma: incremental value versus planar imaging. Journal of Nuclear Medicine $\mathbf{5 0}$ 184-190. (doi:10.2967/jnumed.108.056572)

Tan PK, Chua CL \& Pob WT 1991 Thyroid papillary carcinoma with unusual breast metastasis. Annals of the Academy of Medicine, Singapore 20 801-802. 
Tomoda C, Matsuzuka F \& Miyauchi A 2005 Parapharyngeal metastasis from papillary thyroid carcinoma: a case diagnosed by thyroglobulin measurement in peroral fineneedle aspiration of a cystic metastatic lymph node. Journal of Laryngology and Otology 119 155-157.

Varma D, Jain S \& Khurana N 2007 Papillary carcinoma of thyroid presenting with skin ulceration. Cytopathology 18 260-271. (doi:10.1111/j.1365-2303.2006.00354.x)

Xu Y-H, Song H-J, Qiu Z-L \& Luo Q-Y 2011 $a$ Brain metastases with exceptional features from papillary thyroid carcinoma: report of three cases. Hellenic Journal of Nuclear Medicine 14 44-48.

Xu Y-H, Song H-J, Qiu Z-L \& Luo Q-Y $2011 b^{131}$ I-SPECT/CT found an ovarian metastasis covered by iliac metastasis on ${ }^{131}$ I-WBS in a patient with papillary thyroid carcinoma. Clinical Nuclear Medicine 36 363-364.
Yilmazlar S, Kocaeli H \& Cordan T 2004 Sella turcica metastasis from follicular carcinoma of thyroid. Neurological Research 26 74-78. (doi:10.1179/ 016164104773026561)

Young RH, Jackson A \& Wells M 1994 Ovarian metastasis from thyroid carcinoma 12 years after partial thyroidectomy mimicking struma ovarii: report of a case. International Journal of Gynecological Pathology 13 181-185. (doi:10.1097/00004347199404000-00012)

Received in final form 27 April 2011 Accepted 31 May 2011

Made available online as an Accepted Preprint 1 June 2011 